\title{
Characterizing the impact of fractured caprock heterogeneity on supercritical $\mathrm{CO}_{2}$ injection
}

\author{
Jeffrey D. Hyman, Joaquin Jiménez-Martínez, Carl \\ W. Gable, Philip H. Stauffer, Rajesh J. Pawar
}

6 Received: date / Accepted: date

7 Abstract We present a set of multiphase flow simulations where supercritical $\mathrm{CO}_{2}\left(\mathrm{scCO}_{2}\right)$ 8 displaces water at hydrostatic conditions within three-dimensional discrete fracture networks that represent paths for potential leakage through caprock above $\mathrm{CO}_{2}$ storage reservoirs. The simulations are performed to characterize and compare the relative impact of hydraulic and structural heterogeneity in fractured media on the initial movement of $\mathrm{scCO}_{2}$ through these caprock formations. In one scenario, intrinsic fracture permeabilities are varied stochastically within a fixed network structure. In another scenario, we generate multiple independent, identically distributed network realizations with varying fracture network densities to explore a wide range of geometric and topological configurations. Analysis of the simulations indicates that network structure, specifically connectivity and the presence of hanging fractures, plays a larger role in controlling the displacement of water by $\mathrm{scCO}_{2}$ than variations in local hydraulic properties. We identify active surface area of the network as a single-phase feature that could provide a lower bound on the percentage of the network surface area reached by $\mathrm{scCO}_{2}$.

J. D. Hyman

Computational Earth Science (EES-16), Earth and Environmental Sciences Division, Los Alamos National Laboratory, Los Alamos, New Mexico, USA 87505

E-mail: jhyman@lanl.gov

J. Jiménez-Martínez

Department Water Resources and Drinking Water, EAWAG, 8600 Dubendorf, Switzerland

Department of Civil, Environmental and Geomatic Engineering, ETH Zurich, 8093 Zurich, Switzerland

Earth and Environmental Sciences Division, Los Alamos National Laboratory, Los Alamos, NM, USA 87505

C. W. Gable

Computational Earth Science (EES-16), Earth and Environmental Sciences Division, Los Alamos National Laboratory, Los Alamos, New Mexico, USA 87505

P. H. Stauffer

Computational Earth Science (EES-16), Earth and Environmental Sciences Division, Los Alamos National Laboratory, Los Alamos, New Mexico, USA 87505

R. J. Pawar

Computational Earth Science (EES-16), Earth and Environmental Sciences Division, Los Alamos National Laboratory, Los Alamos, New Mexico, USA 87505 
Keywords Discrete Fracture Networks - Multiphase Flow · Active Surface Area - Carbon Sequestration $\cdot$ Fractured Porous Media

\section{Introduction}

One of the primary risks associated with the long term sequestration of carbon dioxide $\left(\mathrm{CO}_{2}\right.$ ) in geological formations is leakage through the heterogeneous caprock formations that are intended to act as a barrier between storage reservoirs where supercritical $\mathrm{CO}_{2}\left(\mathrm{scCO}_{2}\right)$ is injected and drinking water aquifers residing above them [2,3,6,43]. For geologic sequestration to be effective, the caprock must remain an impermeable barrier that prevents $\mathrm{scCO}_{2}$ from exiting the storage reservoir for thousands of years [46]. There are wide variety of processes that could jeopardize caprock integrity including the reactivation of faults that connect to the reservoir, changes in chemical properties due to $\mathrm{CO}_{2}$-brine-mineral interactions, and changes in the stress field [42]. The initial migration of $\mathrm{scCO}_{2}$ through these systems will primarily occur within the fractures embedded in the caprock matrix, which are the primary pathways for flow and transport in the low permeability caprocks [49]. These fractures form interconnected networks where the range of relevant length scales can span multiple orders of magnitude [9]. At the smallest scale, the roughness of individual fractures can lead to irregular flow fields, which can result in variable precipitation/dissolution and further increase the variability of the flow field [14]. At the largest scale, the network structure and hydraulic gradient determines the overall organization of the flow field [18,28, 25]. In between these two extremes there is the effective permeability of each fracture in the network. However, across all these length scales there is a high degree of uncertainty that must be reduced for the assurance of structural containment and caprock integrity. While the interplay between these length scales is becoming better understood for non-reactive single phase flow, little is known with regard to how reactive transport and multiphase flow are influenced by properties of these fracture networks.

In order to characterize the relative importance of these larger length scale features (network structure and fracture permeability) on multiphase flow behavior and the initial displacement of water by $\mathrm{scCO}_{2}$ in caprock formations, we perform three-dimensional simulations using a high-fidelity discrete fracture network (DFN) simulator where individual fractures are explicitly represented. The choice to use a DFN, rather than a continuum model (dual-permeability/porosity or stochastic continuum) stems from the ability to directly observe how properties of the network impact the organization of the multiphase flow field. We assume that the non-fractured caprock has zero permeability, is non-reactive, and that fractures are the only pathways for fluid flow through the caprock. $\mathrm{scCO}_{2}$ is injected at a constant rate for a 10 years into each network and displaces water in the system to simulate the initial injection and sweep through the networks. We study multiphase fluid flow behavior under two scenarios. In the first, we fix the network geometry and vary hydraulic properties and in the second, we vary network densities and connectivity.

\section{Computational Methods}

We simulate the displacement of water by $\mathrm{scCO}_{2}$ in fractured media using the high-fidelity three-dimensional discrete fracture network modeling suite DFNWORKS [29]. DFNWORKS combines the feature rejection algorithm for meshing (FRAM) [26] and the LAGRIT meshing toolbox [33] to generate three-dimensional fracture networks and create a computational 
mesh representation of the DFN in parallel; each fracture is meshed independently on a different processor. The set of meshed fractures is assembled into a single mesh that is used in the flow simulations. Multiphase flow simulations are performed using the code FEHM [53], which is integrated into DFNWORKS. FEHM is a porous media multiphase flow simulator that can solve fully coupled heat, mass, and stress balance equations. FEHM uses an unstructured control volume finite element discretization approach based on the dual mesh of the conforming Deluanay triangulation of the DFN generated by FRAM. The discretized balance equations are solved using a pre-conditioned Krylov-space solver (GMRES or BCGSTAB) with an Newton-Raphson iteration scheme. FEHM has been used for numerous studies addressing $\mathrm{CO}_{2}$ sequestration $[11,15,32,40,41]$. DFNWORKS has been previously used to study flow and transport in fractured media in a variety of other physical scenarios including hydraulic fracturing operations [31,34,23], inversion of micro-seismicity data for characterization of fracture properties [38], and the long term storage of spent civilian nuclear fuel [22], but this study marks the first time DFNWORKS has been used in problems related to $\mathrm{CO}_{2}$ sequestration.

\subsection{Flow: Supercritical $\mathrm{CO}_{2}$ Simulations}

Each multiphase fluid flow simulation begins at a hydrostatic initial condition, i.e., gravity equilibrium of saturated water in the domain. $\mathrm{scCO}_{2}$ is injected uniformly into the bottom of the fracture network at a constant rate for 10 years to simulate the migration of $\mathrm{scCO}_{2}$ into a caprock formation via the caprock-storage reservoir interface that results from the injection of $\mathrm{scCO}_{2}$ into the storage reservoir residing below. The top of the domain is open so both water and $\mathrm{scCO}_{2}$ can exit through the outlet boundary. All other boundaries are closed; no-flow boundary conditions are applied along all lateral boundaries. We model the displacement of water by $\mathrm{scCO}_{2}$ as two mobile phases. In this context, the governing equations for mass conservation of water are

$$
\frac{\partial}{\partial t} \phi\left[\rho_{\mathrm{CO}_{2}} S_{\mathrm{CO}_{2}} Y_{w}+\rho_{w} S_{w} X_{w}\right]+\nabla \cdot\left[Y_{w} \rho_{\mathrm{CO}_{2}} \mathbf{v}_{\mathrm{CO}_{2}}+X_{w} \rho_{w} \mathbf{v}_{w}\right]=0
$$

where $\phi$ is the porosity, $S$ is the saturation, $\rho$ is the density, $X$ is the fraction of total mass of given component within the water phase, $Y$ is the fraction of the total mass of a given component within the $\mathrm{scCO}_{2}$ gas phase, and $\mathbf{v}$ is the volumetric flux. The subscript $\mathrm{CO}_{2}$ represents the $\mathrm{scCO}_{2}$ and $w$ denotes water. We do not account for the diffusion of $\mathrm{scCO}_{2}$ into the water because our primary focus is the initial displacement of water by $\mathrm{scCO}_{2}$ due to advection and buoyancy rather than the long term behavior of the system. A straightforward calculation of the distance traveled by $\mathrm{scCO}_{2}$ under steady conditions due solely to diffusion is $2.5 \mathrm{~m}$ over 10 years, which compared to the total domain size $(100 \mathrm{~m})$ is negligible. We revisit this choice in the discussion and describe some of the implications.

Similar to (1), the conservation of mass for $\mathrm{CO}_{2}$ is given by

$$
\frac{\partial}{\partial t} \phi\left[\rho_{\mathrm{CO}_{2}} S_{\mathrm{CO}_{2}} Y_{\mathrm{CO}_{2}}+\rho_{w} S_{w} X_{\mathrm{CO}_{2}}\right]+\nabla \cdot\left[Y_{\mathrm{CO}_{2}} \rho_{\mathrm{CO}_{2}} \mathbf{v}_{\mathrm{CO}_{2}}+X_{\mathrm{CO}_{2}} \rho_{w} \mathbf{v}_{w}\right]=0 .
$$

We also apply the following constrains in every computational cell

$$
\begin{gathered}
S_{\mathrm{CO}_{2}}+S_{w}=1 \\
X_{\mathrm{CO}_{2}}+X_{w}=1
\end{gathered}
$$




$$
Y_{\mathrm{CO}_{2}}+Y_{w}=1
$$

We complete the governing equations by assuming that Darcy's law applies for the momentum of each phase

$$
\mathbf{v}_{i}=\frac{k k_{i}}{\mu_{i}}\left(\nabla P_{i}-\rho_{i} \mathbf{g}\right)
$$

and

$$
\widehat{S_{w}}(t)=\int d \Omega S_{w}(t)
$$

denote the total volume of $\mathrm{scCO}_{2}$ and water in the domain, denoted as $\Omega$, at a time $t$. Then, the relative mass fraction (bulk saturation) occupied by $\mathrm{scCO}_{2}$ at a given time $t$ is given by

$$
S_{\mathrm{CO}_{2}}^{\prime}(t)=\frac{\widehat{S_{\mathrm{CO}_{2}}}(t)}{\widehat{\mathrm{SO}_{2}}(t)+\widehat{S_{w}}(t)}
$$

and the relative mass fraction occupied by water is

$$
S_{w}^{\prime}(t)=\frac{\widehat{S_{w}}(t)}{\widehat{\mathrm{SO}_{2}}(t)+\widehat{S_{w}}(t)}
$$

Note that $S_{w}^{\prime}(t)=1-S_{\mathrm{CO}_{2}}^{\prime}(t)$. We also compute the maximum percentage of the network surface area where $\mathrm{scCO}_{2}$ is present over the entire simulation. 


\subsection{Discrete Fracture Networks}

We construct multiple sets of fracture networks to assess how their hydraulic and structural properties influence the behavior of multiphase fluid flow within the system. In the first set of numerical simulations, we fix the network structure and vary the fracture permeabilities. In the second set, we vary the network density and hold intrinsic permeability constant.

In the discrete fracture network modeling methodology, individual fractures are represented as planar $N-1$ dimensional objects embedded within an $N$ dimensional space [5]; here $N=3$. Due to the inherent uncertainty surrounding fracture attributes in the subsurface, e.g., size, shape, aperture, and location, DFN models are constructed stochastically. Fracture shapes, locations, and orientations are sampled from distributions whose parameters are determined by geologic characterization of the formation of interest, cf. [47] for an example. The fractures form a network embedded within an impermeable porous medium. Interactions with the matrix, via diffusion and other mass and energy processes, are not included in these simulations.

Each DFN is constructed in a cubic domain with sides of length 100 meters. Fracture centers are uniformly distributed throughout the domain. During the generation stage, the domain size is slightly increased in all directions to avoid boundary effects and ensure uniform density through the entire domain. The final simulation domain is truncated to a 100 meter cube once the generate phase has completed. The networks are composed of two families of mono-disperse disc-shaped fractures that have a radius of 25 meters. The orientations of the two fracture families are given by the Fisher distribution,

$$
f(\mathbf{x} ; \boldsymbol{a}, \kappa)=\frac{\kappa \exp \left(\kappa \boldsymbol{a}^{T} \mathbf{x}\right)}{4 \pi \sinh (\kappa)},
$$

sampled using the algorithm provided by Wood [52]. In (9), $\boldsymbol{a}$ is the mean direction vector and $\kappa \geq 0$ is the concentration parameter that determines the degree of clustering around the mean direction. Values of $\kappa$ approaching zero represent a uniform distribution on the sphere while larger values generate small average deviations from the mean direction. The first family has parameters $\boldsymbol{a}=(0,0,1)$ and $\kappa=10$ and the second $\boldsymbol{a}=(0,1,0)$ and $\kappa=10$. Thus, the mean orientation of the first family is horizontal in our coordinate systems, which will be perpendicular to the primary direction of flow, while the second family is vertical, which will be parallel to the primary direction of flow. These parameters create a DFN with a block-like structure. We use uniformly sized fractures rather than a distribution of fracture sizes to isolate the effects of variability in hydraulic and structural properties from geometric variations induced by a range of fracture sizes.

An example of one DFN composed of 52 fractures is shown in Fig. 1. Fractures from one family are colored orange, the other family is colored blue, and the conforming Delaunay triangulation is shown in black. The mesh is composed of 122012 triangles with 60505 nodes. This results in 60505 control volumes in the Voronoi tessellation (the dual of the Delaunay triangulation shown here) on which FEHM performs the flow simulation. These Voronoi control volumes are geometrically two-dimensional objects but are computationally treated as three-dimensional volumes by FEHM where the height of the control volumes is the aperture of the fracture. These Voronoi tessellations are in a sense optimal for two-point flux finite volume codes [19] and allow us to use existing finite volume codes for multiphase flow simulations, rather than having to develop numerical methods specifically for DFN modeling, which would otherwise be required. The mesh resolution close to fracture intersections is $0.5 \mathrm{~m}$ and gradually coarsens away from the intersection using the algorithm 
presented in Ushijima-Mwesigwa et. al., [48] where the mesh resolution is a piecewise linear function of distance from intersections on each fracture plane. Gradients in the flow field are higher closer to fracture intersections, which is why we refine the mesh in these regions. We performed an initial set of simulations using a uniform mesh resolution of 0.5 $\mathrm{m}$, i.e., equal sized triangles throughout the DFN, so that numerical diffusion was constant throughout the domain, for comparison with the variable mesh. Differences in our primary quantities of interest, relative mass fraction of the domain occupied by water/ $/ \mathrm{scO}_{2}(8)$, were not substantial in the comparison between mesh resolutions, although there were some local discrepancies in the coarser mesh regions. Therefore, we selected to use a variable mesh resolution to perform more simulations at the same computational cost.

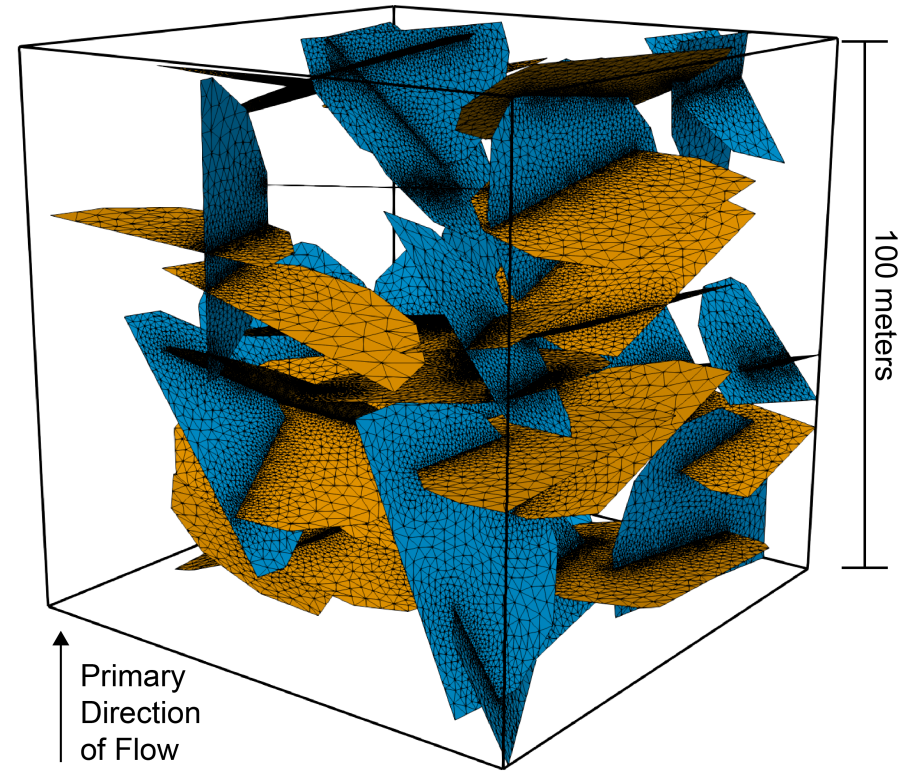

Fig. 1: A DFN composed of 52 fractures drawn from two families of fractures (orange and blue) in a 100 meter cube. The conforming Delaunay triangulation of the DFN is shown in black. In our simulations, the network is initially saturated with water that is displaced by $\mathrm{scCO}_{2}$ injected into the DFN at the bottom of the domain. Thus, the primary direction of flow is from bottom to top.

\subsubsection{Variable Hydraulic Properties}

The first objective of this study is to compare the relative influence of variations in intrinsic permeability between fractures on the displacement of water by injected $\mathrm{scCO}_{2}$. We use the network composed of 52 fractures shown in Fig. 1. We consider one case where the intrinsic permeability of all fractures is the same and three additional cases where the intrinsic permeability varies between fractures. In the case with uniform permeability, we set $k=8.3 \cdot 10^{-12}$ $\mathrm{m}^{2}$. This value corresponds to a hydraulic fracture aperture of $b=10^{-5} \mathrm{~m}$, assuming that the 
Table 1: Static Network Information. $\ln \left(\sigma_{k}\right)$ : $\log$ variance of intrinsic permeability. $P_{32}$ : network intensity. $d_{Q}$ : flow channeling density indicator. $d_{Q} / P_{32}$ : portion of the total surface area where there is a significant flow.

\begin{tabular}{lccc}
\hline $\ln \left(\sigma_{k}\right)$ & $P_{32}\left[\mathrm{~m}^{-1}\right]$ & $d_{Q}\left[\mathrm{~m}^{-1}\right]$ & $d_{Q} / P_{32}[-]$ \\
\hline 0.1 & 0.13 & $0.10 \pm 2.63 \cdot 10^{-3}$ & $0.73 \pm 1.93 \cdot 10^{-2}$ \\
0.5 & 0.13 & $0.09 \pm 7.97 \cdot 10^{-3}$ & $0.67 \pm 5.85 \cdot 10^{-2}$ \\
1.0 & 0.13 & $0.09 \pm 9.45 \cdot 10^{-3}$ & $0.63 \pm 6.94 \cdot 10^{-2}$
\end{tabular}

hydraulic aperture and permeability are related via the cubic law $k=b^{2} / 12$ [51]. In the other three cases, values of the intrinsic permeability are assigned as an independent, identically distributed random variable sampled from a lognormal distribution. The use of a lognormal distribution is motivated by the observation that conductivity values in many natural media are described by a log-normal distribution [44]. We consider three log variances of intrinsic permeability, $\ln \left(\sigma_{k}\right)=0.1,0.5,1.0$, which are small to moderate levels of heterogeneity, and hold the mean value fixed at $8.3 \cdot 10^{-12} \mathrm{~m}^{2}$. When a range of fracture sizes are present, it is typical to correlate larger fractures with wider apertures and less resistance to flow $[8,17$, $24,30,50]$. We do not consider in-fracture aperture variability in these simulations, as was done for single phase simulations by $[18,21,36]$.

A useful measure of fracture networks is the fracture intensity (total fracture surface area per unit volume), which is commonly referred to as $P_{32}$ [16],

$$
P_{32}=\frac{\sum_{f} \cdot S_{f}}{V},
$$

where $S_{f}$ is the fracture surface area and $V$ is the total size of the domain. For this network, $P_{32} \approx 0.13 \mathrm{~m}^{-1}$. The variations in aperture do not significantly influence $P_{32}$; they all remain $\approx 0.13 \mathrm{~m}^{-1}$. However, the influence of these variations can be observed in the distribution of flow at the beginning of the simulations. Recall that all simulations begin fully saturated with water at hydrostatic conditions. We investigate how much of the domain is actively flowing at this point using the flow channeling density indicator $d_{Q}$ presented by Maillot et al. [35]:

$$
d_{Q}=\frac{1}{V} \cdot \frac{\left(\sum_{f} \cdot S_{f} \cdot Q_{f}\right)^{2}}{\left(\sum_{f} \cdot S_{f} \cdot Q_{f}^{2}\right)} .
$$

This definition is inspired by the participation ratio developed in solid state physics $[4,20]$ and has been adapted for use in the geosciences as well [1,12,13]. In (11), $Q_{f}$ is one-half the absolute value of the total volume of fluid exchanged by a fracture $f$ with its neighbors. Comparing (10) with (11) indicates that $d_{Q}$ is a measure of active $P_{32}$ or flowing $P_{32}$ and note that if $Q_{f}$ is uniform across all fractures $d_{Q}=P_{32}$. Thus, the flow channeling indicator is a measure of the portion of the total surface area where there is significant flow, which can be quantified using the ratio $d_{Q} / P_{32}$. Mean and standard deviations for $d_{Q}$ and $d_{Q} / P_{32}$ for the three cases of log variances are provided in Table 1 . In the homogeneous network, $d_{Q}=0.10$ $\mathrm{m}^{-1}$, so $d_{Q} / P_{32}=0.75$, which implies that there is significant flow in $75 \%$ of the network. Although the structure of the network does not change, the active surface area exhibits a dependence on $\ln \left(\sigma_{k}\right)$. As $\ln \left(\sigma_{k}\right)$ increases, the portion of the domain with a significant amount of flow decreases. 


\subsubsection{Network Structure}

The second objective of this study is characterizing the influence of variations in network density on the displacement of water by injected $\mathrm{scCO}_{2}$ in the fracture network. We adopt a graph-based representation of the fracture network to quantify the network structure [27] where each vertex in the graph corresponds to a fracture in the network and there is an edge between two vertices if the corresponding fractures intersect. We augment the graph to include source and target nodes that represent the inflow (bottom of the domain) and the outflow (top of the domain). For any fracture that intersects the bottom/top of the domain, an edge between the corresponding node and the source/target node is added to the graph. We focus on the distribution of fracture degrees, which is the number of other fractures that a fracture intersects, a principal topological trait of the network. In practice, we measure the degree of the corresponding node in the graph, i.e., number of edges attached to that node.

We consider thirty network realizations at three different densities with uniform fracture apertures. In the lowest density, generation of the network is stopped once 100 fractures are accepted into network. Note, that this is not the final number of fractures in the simulation because isolated fractures, those that are not in a cluster that connects inflow to outflow boundaries, are removed because they do not contribute to flow. In the second network set, generation of the network is stopped once 200 fractures are accepted into network. In the third network set, generation of the network is stopped once 400 fractures are accepted into network. The final number of fractures in each set are reported in Table 2 . The intrinsic permeability of all fractures is the same and equal to $k=8.3 \cdot 10^{-12} \mathrm{~m}^{2}$.

The selected generation parameters lead to differences in the network density. There are a variety of definitions and measurements for network density, and we adopt the dimensionless form of density $\chi^{\prime}$ defined by Mourzenko et al. [37], which is the mean of the distribution of fracture degrees (values and standard deviations reported in Table 2). Note, however, that the reported values are for the DFN used in the flow simulations where isolated clusters of fractures have been removed. As the number of fractures increases, so does $\chi^{\prime}$, but the variations are not drastic. Figure 2 shows the distribution of fracture degrees and highlights the disparity between the networks, even though $\chi^{\prime}$ is roughly the same. In the lowest density networks, almost all fractures have low degree and the maximum degree is seven. In contrast, the high density network is also primarily composed of fractures with low degree, but there are a significant number of fractures with higher degree. Thus, in general as the number of fractures in the domain increases, the networks are better connected. In the lowest density network $28 \%$ of fractures in the network are dead-end fractures, in the medium density, $22 \%$ of fractures are dead-ends, and in the highest density only $9 \%$ of the fractures are dead ends. Here we define the dead-ends as being fractures who are the compliment of the network 2-core, which is the maximal subgraph where all nodes have degree 2 or larger [45], and is formal definition of the natural definition of dead-ends.

We also measure the local node connectivity $n_{c}$ with respect to the inflow and outflow boundaries. Local node connectivity is a scalar value of a graph that corresponds to the fewest number of vertices that have to be removed so that two other vertices are disconnected. Physically, it corresponds to the fewest number of fractures that need to be removed from the DFN so that the bottom and top are disconnected and can be thought of as a measure of robustness in the network and structurally imposed channelization. In the low density networks, the mean value of $n_{c}$ is close to 1 , which indicates a single connected path of fractures from inflow to outflow. In the high density networks, the mean value of $n_{c}$ is close to 6 , thereby indicating that there are numerous pathways between inflow to outflow. 
Table 2: Network Information. $n_{f}$ : number of fractures. $\chi^{\prime}:$ mean of fracture degree. $n_{c}:$ local node connectivity. $P_{32}$ : network intensity. $d_{Q}$ : flow channeling density indicator. $d_{Q} / P_{32}$ : portion of the total surface area where there is a significant flow.

\begin{tabular}{l|ccc|ccc}
\hline Set & $n_{f}$ & $\chi^{\prime}$ & $n_{c}$ & $P_{32}\left[\mathrm{~m}^{-1}\right]$ & $d_{Q}\left[\mathrm{~m}^{-1}\right]$ & $d_{Q} / P_{32}[-]$ \\
\hline 1 (lowest density) & $38.23 \pm 14.97$ & $2.39 \pm 0.17$ & $1.47 \pm 0.72$ & $0.09 \pm 0.04$ & $0.05 \pm 0.02$ & $0.50 \pm 0.14$ \\
2 (medium density) & $118.96 \pm 13.57$ & $2.89 \pm 0.13$ & $3.03 \pm 1.08$ & $0.25 \pm 0.03$ & $0.11 \pm 0.03$ & $0.44 \pm 0.09$ \\
3 (highest density) & $202.00 \pm 15.12$ & $3.29 \pm 0.11$ & $5.79 \pm 1.42$ & $0.38 \pm 0.02$ & $0.18 \pm 0.02$ & $0.47 \pm 0.05$
\end{tabular}

Mean and standard deviations of $P_{32}, d_{Q}$, and $d_{Q} / P_{32}$ are also reported in Table 2. $P_{32}$ and $d_{Q}$ increase with network density. There is more variation between realizations at lower density as well. At the lowest density, the flow tends to be more channelized due to the lower connectivity of the networks. As the density rises the flow becomes more disperse and homogeneous. This homogenization of the flow fields between realizations is the result of better-connected networks. These two processes balance one another and the mean of the ratio $d_{Q} / P_{32}$ does not change significantly with density. Note that $d_{Q} / P_{32}$ is a ratio of flow rates as well, so all things are relative the network at hand. Additionally, there is more disparity amongst the low density networks than the higher density ones.

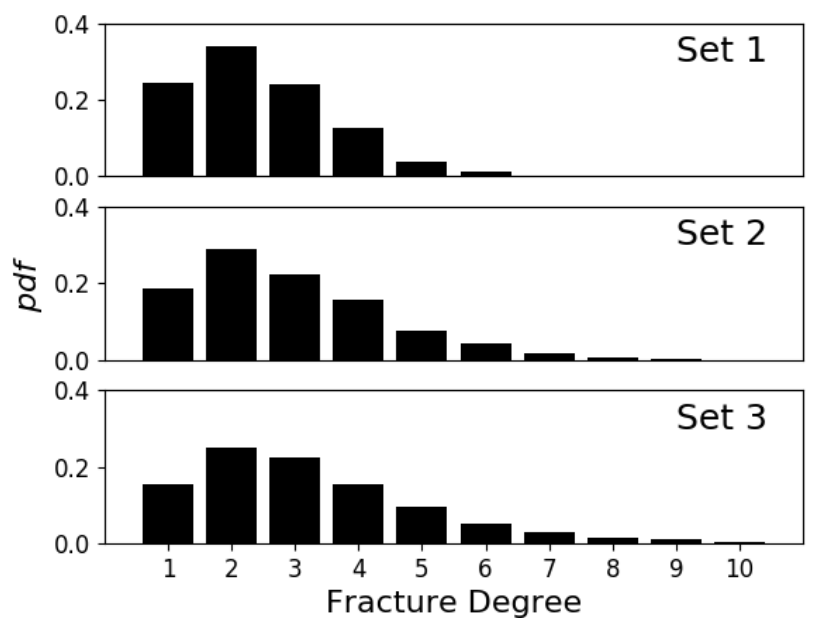

Fig. 2: Fracture degree distributions. Top: set 1, Middle: set 2, Bottom: set 3. The degree of a fracture is the number of other fractures that it intersects. In the low density networks (top) almost all fractures have low degree. The highest density networks (bottom) are also primarily composed of fractures with low degree, but there are a significant number of fractures with rather high degree. Thus, in general, as the number of fractures in the domain increases, the networks become more connected. 


\section{Results}

We begin with a discussion of flow in the single network with homogeneous properties, then proceed to the variable hydraulic properties, and conclude with simulations in multiple networks with various densities.

\subsection{Single Network}

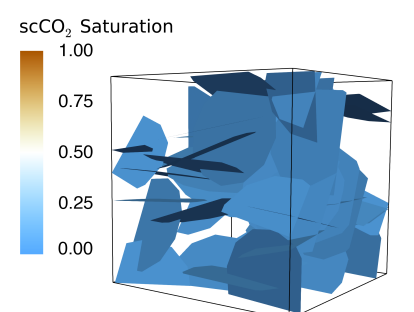

Time: 0.00 days

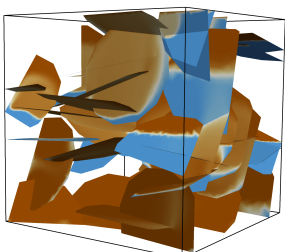

Time: 2.00 days

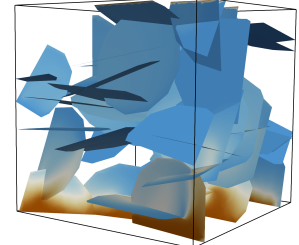

Time: 0.10 days

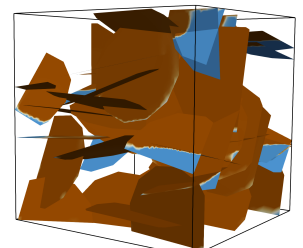

Time: 10.00 days

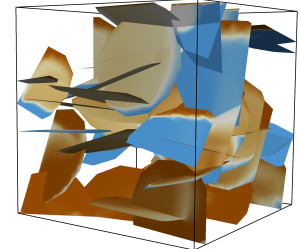

Time: 1.00 days

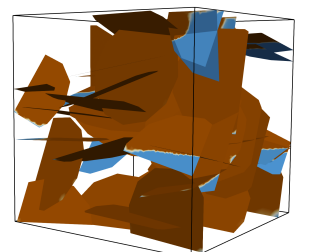

Time: 3650.00 days

Fig. 3: Snapshots of $\mathrm{scCO}_{2}$ displacing water in a DFN with constant permeability. $\mathrm{scCO}_{2}$ is injected at a constant rate into the domain through fractures connected to the bottom. The $\mathrm{scCO}_{2}$ rises through the network displacing water. Quasi-steady state conditions are reached after $\approx 10$ days in the 10 year simulation. At this point, the majority of the domain is fully saturated with $\mathrm{scCO}_{2}$ but there are some regions (hanging fractures) that remain fully saturated with water.

Six images of the simulation results at different times in the fixed geometry with uniform permeability are shown in Fig. 3. The DFN is colored by $\mathrm{scCO}_{2}$ saturation which ranges between $[0,1]$. Light blue indicates a region is fully saturated with water and brown is fully saturated with $\mathrm{scCO}_{2}$. The initial condition, fully saturated with water, is shown in the top left subfigure. After $\approx 0.1$ days (top middle subfigure), the $\mathrm{scCO}_{2}$ being injected into the domain through fractures connected to the bottom becomes visible and starts to displaces water. At $\approx 1$ days (top right subfigure), $\mathrm{scCO}_{2}$ has entered more of the domain, in part due to buoyancy and in part due to the constant injection at the bottom. At $\approx 2$ days (bottom left subfigure) $\mathrm{scCO}_{2}$ has reached the top of the domain and nearly fully saturated the bottom of the domain. The system has reached a quasi steady-state by $\approx 10$ days (bottom middle subfigure); there is little change between this time and the end of the simulation (bottom right subfigure). Nearly the entire DFN is fully saturated with $\mathrm{scCO}_{2}$. However, there are 
some regions where the $\mathrm{scCO}_{2}$ has not displaced the water. These regions tend to be below (with respect to the $z$ axis) lines of intersection with a fracture.

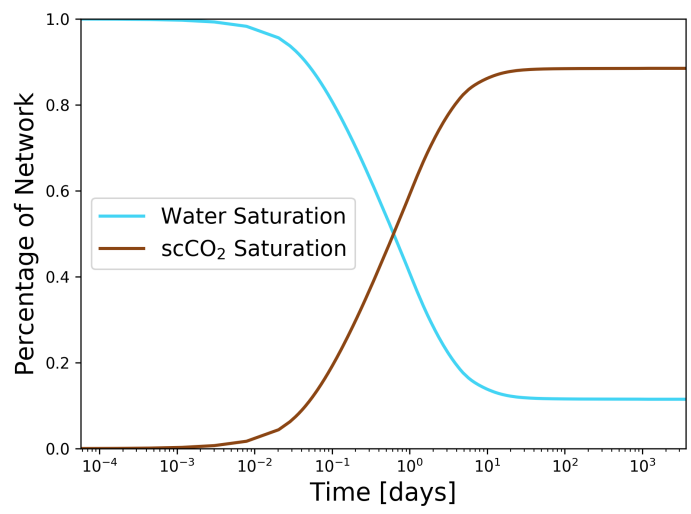

Fig. 4: Bulk saturation in the network. $\mathrm{scCO}_{2}$ (brown) displacing water (blue) in the DFN shown in Fig. 3. At the end of the simulation, $\mathrm{scCO}_{2}$ occupies $89 \%$ of the DFN.

Figure 4 reports the bulk saturation in the network, (7) and (8), for the simulation shown in Fig. 3 (blue-water, and brown-scCO 2 ). After $\approx 1$ day, there is more $\mathrm{scCO}_{2}$ in the DFN than water. After $\approx 10$ days, the system has reached a quasi-steady state, indicated by the stabilization of the saturation volumes. Notice that the domain does not become fully saturated with $\mathrm{scCO}_{2}$. Rather, only $89 \%$ of the DFN is filled with $\mathrm{scCO}_{2}$ with water remaining in the rest of the domain. The regions that are not flushed by $\mathrm{scCO}_{2}$ are hanging fractures, fractures whose intersections with others in the domain are at a higher elevation than other portions of the fracture. We explore this phenomenon in the following subsection using a simple network.

\subsubsection{Hanging Fractures}

To highlight the influence of hanging fractures on sweep efficiency, the volume of water pushed out of the network or equivalently final percentage of the network occupied by $\mathrm{scCO}_{2}$, we construct the five fracture network shown in Fig. 5. All fractures have the same permeability $\left(k=8.3 \cdot 10^{-12} \mathrm{~m}^{2}\right)$. The network has one primary fracture (labeled-1) connecting the bottom of the domain (inflow) to the top of the domain (outflow). Fracture 1 is intersected by two fractures (labeled 2 and 4) that intersect two additional fractures (labeled 3 and 5). In this network, portions of fractures 3, 4, and 5 are hanging fractures. Note, as well, that all of the secondary fractures are dead-end subnetworks, they do not connect back to the primary network.

We perform the same numerical simulations in this network as in the more complicated ones to illustrate the interplay between dead-end fractures, hanging fractures, and the movement of $\mathrm{scCO}_{2}$. A snapshot at an early time in the simulation is shown in the left sub-figure. $\mathrm{scCO}_{2}$ is injected at the bottom of fracture 1 and colors are the same as in Fig. 3. Water in the primary fracture is quickly displaced. The middle sub-figure shows a later time in the 


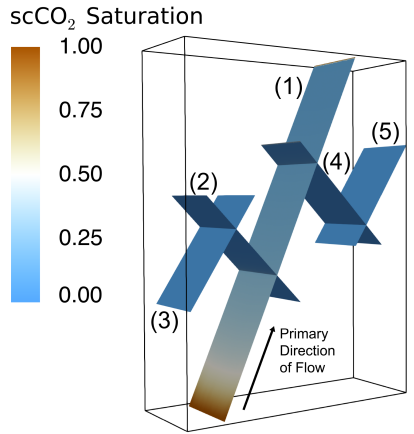

Time: 0.05 days

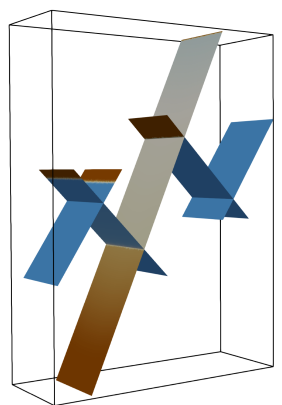

Time: 0.50 days

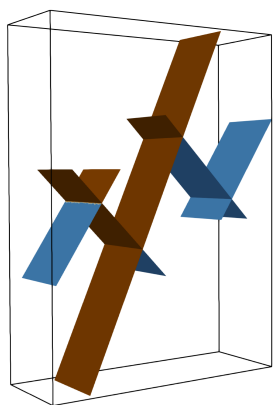

Time: 5.00 days

Fig. 5: Simulation snapshots of $\mathrm{scCO}_{2}$ displacing water in a DFN composed of 5 fractures. The primary fracture (1) is connected to two sets of hanging fractures (2-3) and (4-5). At the end of the simulation, the primary fracture and regions of subnetworks are fully saturated with $\mathrm{scCO}_{2}$ but the hanging portions of fractures remain fully saturated with water, having never been accessible to $\mathrm{scCO}_{2}$ due to buoyancy effects.

simulation where the non-hanging regions of fractures 2,3 , and 4 are fully saturated with $\mathrm{scCO}_{2}$ but other regions of fractures 3 and 4 remain fully saturated with water. The accessibility of some regions and not others is due to buoyancy of $\mathrm{scCO}_{2}$ that allows $\mathrm{scCO}_{2}$ to rise into these regions. Regions above the lines of intersection are accessible while the regions below them are not. Note that all of these regions are portions of dead-end subnetworks that conventional wisdom suggests to be no-flow regions. However, that is clearly not the case here due to (a) multiphase flow effects, specifically buoyancy, and (b) that the DFN is threedimensional. At the end of the simulation (right sub-figure) fracture 1,2, and pieces of 3 and 4 are fully saturated with $\mathrm{scCO}_{2}$ but the rest of the domain is saturated with water. In particular, fracture 5, while not technically a hanging fracture, remains fully saturated with water because fracture 4 , which connects to the primary fracture is a hanging fracture, and $\mathrm{scCO}_{2}$ cannot enter the lower region. This example highlights that the geometric and topological structure of the fracture network plays a principal role in initial sweep efficiency, even in the absence of hydraulic variability. At longer times, diffusion of $\mathrm{scCO}_{2}$ into the water will occur, and the hanging fractures will contain a mixture of water with dissolved $\mathrm{scCO}_{2}$ at equilibrium saturation, which depends on the pressure and temperature of the system.

While the conceptual definition of a hanging fracture is rather straightforward, the identification of these regions within a complex DFN is not. Unless an intersection crosses entirely through a fracture thereby partitioning it into two disjoint regions, the hanging regions are geometrically ambiguous. Moreover, multiple intersections on a fracture obfuscate their location more so. Unlike the five-fracture example presented in this subsection, where hanging fractures are obvious and clearly defined, their identification in more complicate DFNs are difficult to rigorously define. 
3.2 Variable Hydraulic Properties

Next we characterize the impact of variable hydraulic properties on how $\mathrm{scCO}_{2}$ displaces water. In these simulations, the network geometry is fixed and we vary permeability between fractures; permeability within each fracture is constant but varies between fractures. We consider three $\log$ variances of permeability $(0.1,0.5,1.0)$ and thirty realizations of the permeability field at each log variance.

Figure 6 shows snapshots from four simulations 1 day into the simulation. The top-left subfigure is the constant permeability scenario, which is used as a control case for comparison. At this time in the simulation, $57.1 \%$ of the network is saturated with $\mathrm{scCO}_{2}$. The other subfigures are realizations where (top-right) $\ln \left(\sigma_{k}\right)=0.1$ is $58 \%$ saturated with $\mathrm{scCO}_{2}$, (bottom-left) $\ln \left(\sigma_{k}\right)=0.5$ is $56.5 \%$ saturated with $\mathrm{scCO}_{2}$, and (bottom-right) $\ln \left(\sigma_{k}\right)=1.0$ is $53.2 \%$ saturated with $\mathrm{scCO}_{2}$, The influence of fracture to fracture variability subtle but present. The realization with $\ln \left(\sigma_{k}\right)=0.1$ has slightly more $\mathrm{scCO}_{2}$ than the control case, while the realization with $\ln \left(\sigma_{k}\right)=1.0$ has less. In this particular realization, the case with $\ln \left(\sigma_{k}\right)=0.5$ has about the same amount as the control case. Thus, the amount of $\mathrm{scCO}_{2}$ in the domain relative to the control case is realization dependent, a feature that we explore next.

The variations between realizations at a value of $\ln \left(\sigma_{k}\right)$ is demonstrated in Fig. 7, which shows the bulk saturation in the networks; (left) $\ln \left(\sigma_{k}\right)=0.1$, (middle) $\ln \left(\sigma_{k}\right)=0.5$, and (right) $\ln \left(\sigma_{k}\right)=1.0$. The bulk saturation in the constant permeability case is included in each sub-figure as a thick line while the individual profiles from each realization is a semitransparent line. In the case of $\ln \left(\sigma_{k}\right)=0.1$, the simulations center around the control case. In some realizations there is slightly more $\mathrm{scCO}_{2}$ saturation at the end of the simulation than in the control case and there are others where there is slightly less. The mean of the final values, along with standard deviation, is provided in Table 3 . There are larger variations when $\ln \left(\sigma_{k}\right)=0.5$ (middle sub-figure) than $\ln \left(\sigma_{k}\right)=0.1$ and even larger variations $\operatorname{in} \ln \left(\sigma_{k}\right)=1.0$. For $\ln \left(\sigma_{k}\right)=1.0$, there are a few realizations where the final fracture of the domain filled with $\mathrm{scCO}_{2}$ is higher than the control case but most conclude with a lower fracture of the domain being saturated with $\mathrm{scCO}_{2}$. Note, that there are also deviations from the control case at early times as well as late times. This observation of limiting behavior can be attributed to the geometric and topological constraints imposed on the flow field by the network structure and, in particular, the hanging fractures previously discussed. Specifically, if a hanging fracture is assigned a lower permeability, it will act as a bottleneck making more of the network less accessible to $\mathrm{scCO}_{2}$. Homogeneity in the distribution of $\mathrm{scCO}_{2}$ in each network can be measured using the coefficient of variation $C_{v}$ (standard deviation over the mean) of the relative mass fraction occupied by $\mathrm{scCO}_{2}$ on each fracture across each the network at the end of the simulation; higher values indicate more variation across fractures within a network. As the log variance increases, so does $C_{v}$ indicating that larges variations in the hydraulic heterogeneity result in more heterogeneity in the distribution of $\mathrm{scCO}_{2}$ within the networks.

Figure 8 shows the maximum percentage of the network surface area containing $\mathrm{scCO}_{2}$ over time for all realizations plotted as a function of $d_{Q} / P_{32}$ : the percentage of the network at the beginning of the simulation where there is significant flow. The constant permeability network $\ln \left(\sigma_{k}\right)=0.0$ is represented by a black circle, $\ln \left(\sigma_{k}\right)=0.1$ : blue diamonds, $\ln \left(\sigma_{k}\right)=$ 0.5 : green triangles, $\ln \left(\sigma_{k}\right)=1.0$ : red squares. In all cases the marker are above the 11 line, indicating that $d_{Q} / P_{32}$ is a lower bound on the surface area reached by $\mathrm{scCO}_{2}$ in this network regardless of the intrinsic permeabilities we consider. There is more spread in $d_{Q} / P_{32}$ compared to the final $\mathrm{scCO}_{2}$ percentage across the ensemble of samples. A possible explanation for this observation is that the multiphase flow features that are not present in 
$\mathrm{scCO}_{2}$ Saturation
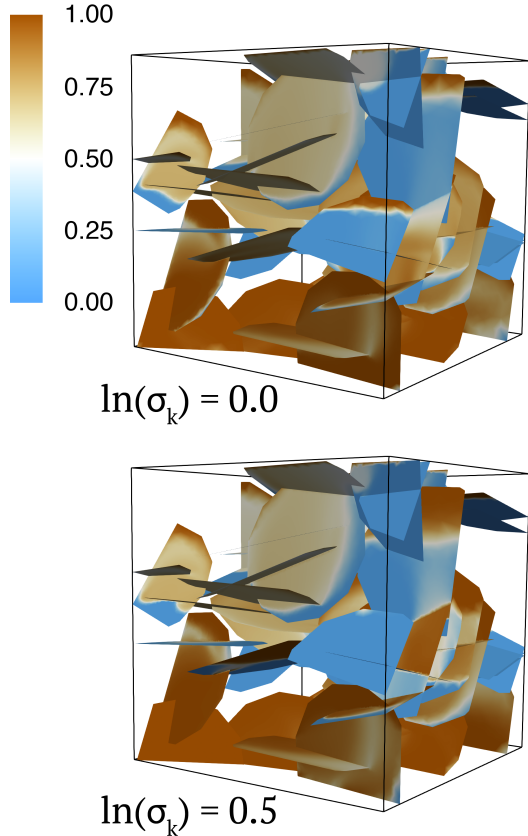
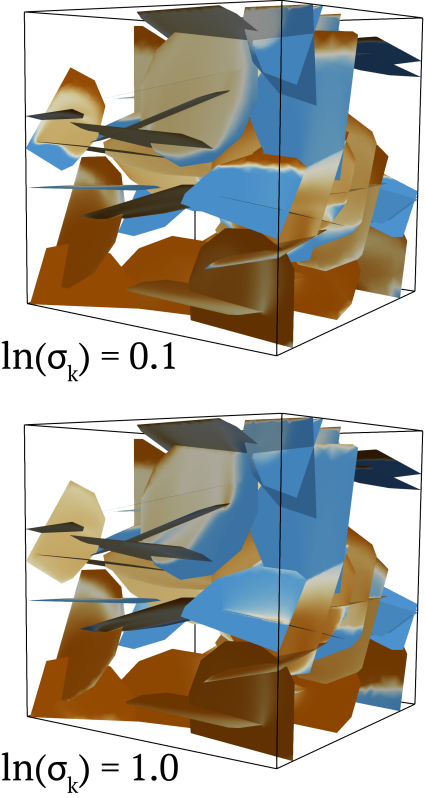

Fig. 6: Simulation of $\mathrm{scCO}_{2}$ displacing water 1 day into the simulation in the same DFN with varying levels of hydraulic heterogeneity. Fracture permeabilities are sampled from a $\log$ normal distribution with $\log$ variance of (top-left) $\ln \left(\sigma_{k}\right)=0.0$ (top-right) $\ln \left(\sigma_{k}\right)=0.1$ (bottom-left) $\ln \left(\sigma_{k}\right)=0.5$ (bottom-right) $\ln \left(\sigma_{k}\right)=1.0$. The variability in permeability can both enhance and inhibit the rate at which $\mathrm{scCO}_{2}$ displaces water.
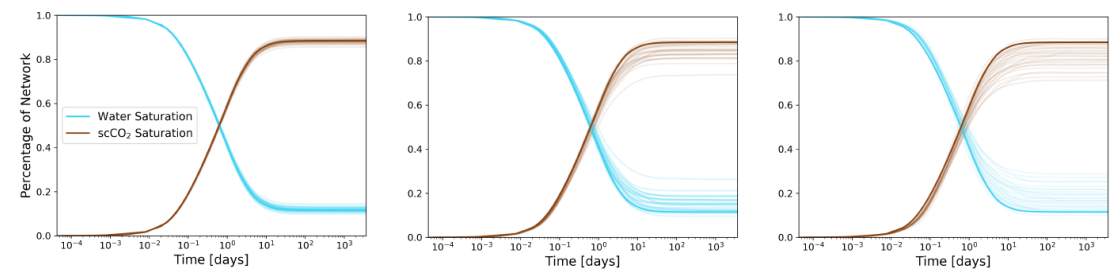

Fig. 7: Relative saturation curves in simulations with varying fracture permeability in the same network geometry. Different log-variances are shown in each sub-figure (left) $\ln \left(\sigma_{k}\right)=0.1$, (middle) $\ln \left(\sigma_{k}\right)=0.5$, (right) $\ln \left(\sigma_{k}\right)=1.0$. The bulk saturation in the constant permeability case is included in each sub-figure as a thick line while the individual profiles from each of the thirty realization are semi-transparent lines. As the log-variance increases, there is more variability between realizations are larger variants from the constant case. 
Table 3: Simulation results for a fixed network geometry and varying levels of hydraulic heterogeneity. Final $\mathrm{scCO}_{2}$ : fraction of the domain filled $\mathrm{scCO}_{2}$ after 10 years. $C_{v}$ : Coefficient of variation

\begin{tabular}{lllll}
$\ln \left(\sigma_{k}\right)$ & Final scCO & & & \\
\hline & mean \& std. dev & $\max$ & $\min$ & $C_{v}$ \\
\hline 0.0 & $0.89 \pm 0.00$ & 0.89 & 0.89 & $0.32 \pm 0.00$ \\
0.1 & $0.88 \pm 0.01$ & 0.90 & 0.86 & $0.32 \pm 0.01$ \\
0.5 & $0.85 \pm 0.03$ & 0.90 & 0.74 & $0.35 \pm 0.04$ \\
1.0 & $0.82 \pm 0.05$ & 0.90 & 0.74 & $0.36 \pm 0.06$
\end{tabular}

single phase, e.g., buoyancy, allow for the $\mathrm{scCO}_{2}$ to reach areas that are more or less no-flow regions in single phase and homogenize the structural heterogeneity of the network.

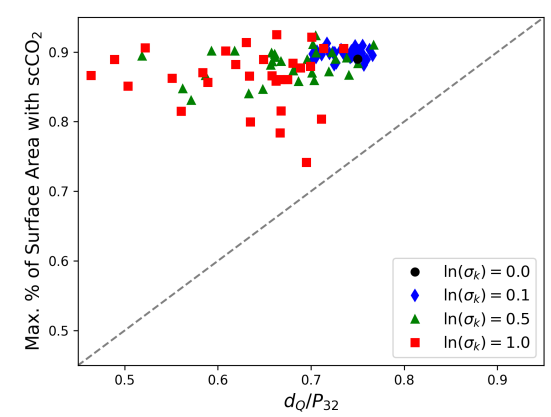

Fig. 8: Maximum percentage of the network surface area containing $\mathrm{scCO}_{2}$ plotted against $d_{Q} / P_{32}$ (active surface area in the single phase simulations in the same domain). The values of $d_{Q} / P_{32}$ provide a lower bound on the percentage of the network surface area reached by $\mathrm{scCO}_{2}$.

\subsection{Variable Structural Properties}

In this section, we compare simulation results for networks with different densities but constant permeability throughout the network. For each density, we generate thirty independent network realizations. Figure 9 shows snapshots of the simulations in three networks, one from each of the densities considered: (left) set 1: lowest density, (middle) set 2: middle density, (right) set 3: highest density, 1 day into the simulation. The sample from set 1 (left) is the network with constant permeability used in section 3.1. At this time in the simulation, there fractures in the system that contain very little $\mathrm{scCO}_{2}$ and others that are nearly fully saturated, i.e., there is heterogeneous distribution of $\mathrm{scCO}_{2}$ due to the connectivity of the fracture network. As the density increases, this heterogeneity decreases and $\mathrm{scCO}_{2}$ is more uniformly distributed throughout the system. This homogeneity can be measured using the coefficient of variation (standard deviation over the mean) of the relative mass fraction occupied by $\mathrm{scCO}_{2}$ on each fracture across each the network at the end of the simulation; higher 
values indicate more variation across fractures within a network. In the lowest density case the mean (with standard deviation) of the coefficient of variation across the ensemble of networks is $0.56 \pm 0.34$, for the medium it is $0.52 \pm 0.13$, and the highest density is $0.39 \pm 0.09$. These values indicate that not only is the distribution of $\mathrm{scCO}_{2}$ more uniform across the higher density networks, but that higher density networks are more similar to one another. A principal reason for this homogenization is that fractures are better connected so there are more pathways for $\mathrm{scCO}_{2}$ to enter and exit fractures. In the highest density sample, the distribution of $\mathrm{scCO}_{2}$ is fairly uniformly, which the exception of edge effects (both fracture and domain).
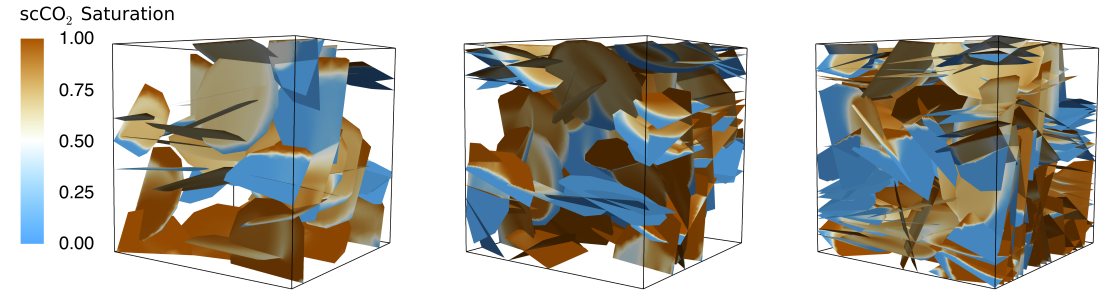

Fig. 9: Simulation snapshot after 1 day for three networks with various densities: low (left) medium (middle) and high (right) high.scCO $\mathrm{CO}_{2}$ is more uniformly distributed at higher densities.

The bulk saturation in the networks in these simulations are provided in Fig. 10; (left) lowest density (middle) middle density, (right) highest density. The mean of the final values of $\mathrm{scCO}_{2}$, along with standard deviation, are provided in Table 4 along with minimum and maximum values. There is a large amount of variation between realizations in set 1 - the lowest density. There are some networks where the final $\mathrm{scCO}_{2}$ is less than $40 \%$, while others are almost at $100 \%$. In this set of networks, the sparsity results in the flow of $\mathrm{scCO}_{2}$ being primarily controlled by the structure of the network. Many of the fractures that make up these networks have few connections and therefore the options for inflow and outflow configurations within these fractures are limited. Moreover, many fractures in these networks are either hanging fractures or have portions of fractures that are hanging and thus not accessible to $\mathrm{scCO}_{2}$ at the short time scales considered. In set 2, the bulk saturations profiles are more uniform than in the low density case, but there is still some variation between samples. Simulations in the set 3 (highest density) are more or less similar, especially when compared to the low density networks. In sets 2 and 3, there are fewer hanging fractures / hanging portion of the fractures. The regions that are hanging tend to be close to the domain boundaries and the lack of accessibility appears to be the consequence of boundary effects. If we considered open lateral boundaries, it would allow more $\mathrm{scCO}_{2}$ to flow through the domain and delay the arrival at quasi-steady state and these small numerical boundary effects would be eliminated, but the final flow field would be relatively unaffected.

Figure 11 shows the maximum percentage of the network surface area occupied by $\mathrm{scCO}_{2}$ plotted as a function of $d_{Q} / P_{32}$ : the percentage of the network at the beginning of the simulation where there is signification flow, cf. Fig. 8. Set 1 is indicated by red square markers, set 2- blue diamonds, and set 3-green triangles. There is the highest amount of 

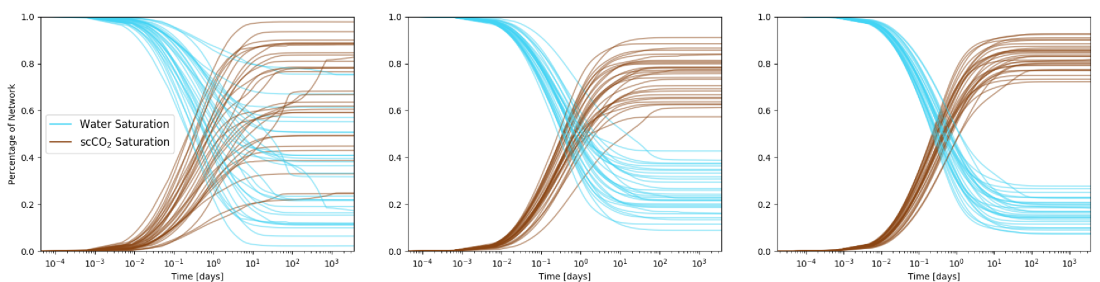

Fig. 10: Bulk saturation curves for variable density networks low (left) medium (middle) and high (right) high. As the density of the networks increases, there is less variability between network realizations.

Table 4: Simulation results for a multiple network geometries with varying densities (1low density, 2-medium density, 3-high density) and fixed hydraulic properties. Final $\mathrm{scCO}_{2}$ : amount of the domain filled $\mathrm{scCO}_{2}$ after 10 years. $C_{v}$ : Coefficient of variation

\begin{tabular}{lllll} 
Network Set & Final $\mathrm{scCO}_{2}$ & & & \\
\hline & mean \& std. dev & $\max$ & $\min$ & $C_{v}$ \\
\hline 1 & $0.67 \pm 0.21$ & 0.98 & 0.25 & $0.56 \pm 0.34$ \\
2 & $0.75 \pm 0.09$ & 0.91 & 0.57 & $0.52 \pm 0.13$ \\
3 & $0.83 \pm 0.05$ & 0.93 & 0.72 & $0.39 \pm 0.09$
\end{tabular}

scatter in set 1 , which is the lowest density. In all but one network, markers are above the 1-1 line, indicating that $d_{Q} / P_{32}$ is less than maximum percentage of surface area occupied by $\mathrm{scCO}_{2}$. For this set, there is 1 out of 30 where $d_{Q} / P_{32}$ is greater than the final percentage of the network saturated by $\mathrm{scCO}_{2} ; 0.61$ compared to 0.54 . For both sets 2 and $3, d_{Q} / P_{32}$ is less than the maximum percentage of surface area occupied by $\mathrm{scCO}_{2}$ in all simulations. Similar to what was observed in the case of varying hydraulic properties, $d_{Q} / P_{32}$ appears to provide a lower bound on the final percentage of the network surface area where $\mathrm{scCO}_{2}$ is present. Note that, however, this bound appears to depend on the network density. At higher densities, the bound holds for all networks, but not at lowest density, where there is an out-lier, which is discussed below. Moreover, we again observe that there is more spread in $d_{Q} / P_{32}$ compared to the final $\mathrm{scCO}_{2}$ percentage across the ensemble of samples due to multiphase flow features.

The one network out of ninety where the lower bound did not hold presents some interesting features that could provide insights into the conditions where this apparent bound breaks down. First, the network is poorly connected having only a single path from inlet to outlet. Second, the area of the inlet region is consists of a single fracture with a short region connecting to the inlet plane. The results is fairly small surface area where $\mathrm{scCO}_{2}$ travel into the domain and through. The coefficient of variation for the distribution of $\mathrm{scCO}_{2}$ in this network is 0.86 , which indicates a higher degree of heterogeneity in final flow state on this particular network than others at this density. In the case of single phase flow, the flow spreads out across the fractures and the flow path in terms of fractures taken by $\mathrm{scCO}_{2}$ is the same as where there is activity in single phase. 


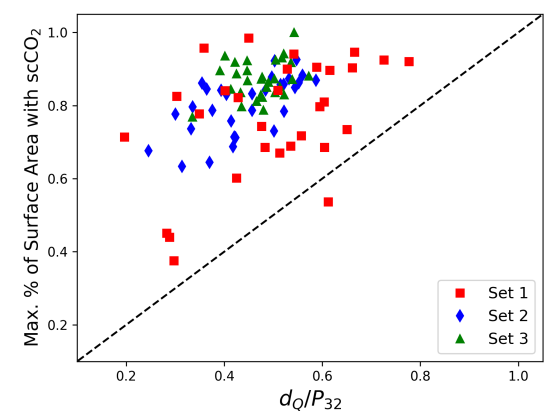

Fig. 11: Maximum percentage of the network surface area occupied by $\mathrm{scCO}_{2}$ plotted against $d_{Q} / P_{32}$ (active surface area in the single phase simulations in the same domain). For sets 2 and 3 , the values of $d_{Q} / P_{32}$ provide a lower bound on the percentage of the network fully saturated by $\mathrm{scCO}_{2}$. In the case of set 1 , this bound holds with one exception.

\section{Discussion \& Conclusions}

We presented a set of numerical simulations performed to study the displacement of water at hydrostatic conditions by $\mathrm{scCO}_{2}$ injected into three-dimensional discrete fracture networks. We considered two physical scenarios. In the first, the network geometry is held constant and the hydraulic properties of the network are varied stochastically. In the second, independent, identically distributed network realizations are generated at various densities with constant permeability. The results demonstrate that variations in hydraulic properties, e.g., fracture permeability, and structural, e.g., network density, can both impact displacement of water by $\mathrm{scCO}_{2}$ in a fracture network. In particular, the following relationships were observed:

1. At long times, once the simulations reach a quasi steady-state, the regions of the DFN fully saturated by $\mathrm{scCO}_{2}$ are determined by network structure and fluid properties. Specifically, hanging fractures and portions of fractures that are below fracture intersections, which is a geometric and topological property of the network, are not accessible to $\mathrm{scCO}_{2}$ due to buoyancy, which is a property of the fluid. However, at longer times, diffusion of $\mathrm{scCO}_{2}$ into the water will occur, and the hanging fractures will contain a mixture of water with dissolved $\mathrm{scCO}_{2}$ at equilibrium saturation, which depends on the pressure and temperature of the system. Also, note that these simulations were primarily vertically upwards flow and if the primary flow direction was changed, the effects of buoyancy could be different.

2. For a fixed network geometry, variations in intrinsic permeability between fractures can both enhance and inhibit the displacement of water. As the variance of the permeability distribution increases, the variations in bulk saturation of the networks and final distribution of the phases between realizations is more pronounced. Moreover, variations in the volume of the domain where both phases are present is influenced in a similar manner. The residual water in the system is typically larger with higher log variance. This final point is due to lower permeabilities being assigned to choke points, which are fractures that control the accessibility to hanging fractures and dead-end subnetworks at early times. 
3. Changes in the network density have a significant impact on the displacement of water. At low densities, the networks are more heterogeneous across the ensemble and unique attributes of the fracture network are reflected in the saturation profiles observed in the networks. In this set of networks, the highest variation between realizations was observed. These networks have numerous hanging fractures, which are not accessible to $\mathrm{scCO}_{2}$, and dead-end subnetworks, which are less accessible but not entirely inaccessible. As the density of the networks increases, so does the connectivity between fractures. Thus, dead-end subnetworks and hanging fractures are eliminated, and more of the DFN is accessible to $\mathrm{scCO}_{2}$. In turn there is more uniformity between DFN realizations and structural aspects of the individual fractures become less important.

4. In comparison, variations in the network structure, such as density and topology, have a more pronounced impact on how water is displaced in fracture networks than variations in fracture permeability for the moderate values of hydraulic heterogeneity we considered. These variations appear to primarily be the result of hanging fractures, which cannot become significantly more accessible to higher permeability, but can become better connected as the network density increases.

5. Our results indicate a possible attribute of single phase simulations, namely the active surface area, that could provide a lower bound on the maximum percentage of the network surface area that $\mathrm{scCO}_{2}$ reaches. A possible explanation for this relationship is that the combination of injection and buoyancy allows $\mathrm{scCO}_{2}$ to reach areas in the network that are more or less no-flow regions in single phase. This bound is observed for all cases of variable permeability and in the higher density networks (sets 2 and 3 in the variable DFN case). However, the bound does not old for all networks at the lowest densities. The one exceptions is in a rather sparse network with a single pathways from inlet to outlet where many of the fractures are poorly connected. In this network, the flow of $\mathrm{scCO}_{2}$ is highly channelized and does not disperse through the network evenly. While the bound is not firm, this observation does lend to providing a starting point to estimate what percentage of the network surface will be accessed by injected $\mathrm{scCO}_{2}$. However, we have only considered three densities of uniformly sized fractures. Additional network structures with a range of geological attributes, e.g., variability length distributions along with lower and higher densities, are needed to further explore the causes of this relationship and its limitations.

We designed these simulations to isolate the effects of two hypothesized principal controls on multiphase flow through fractured media, hydraulic and structural heterogeneity. There are numerous extensions to these simulations that will build off of the presented results to identify and rank additional features and their impact on multiphase flow in fracture networks. At large scales, performing simulations with fractures of variable sizes, i.e., radii following a powerlaw or lognormal distribution, is critical to advance our understanding of the interplay of geometry and multiphase flow behavior. At the opposite scale, the influence of in-fracture aperture variability on capillary pressures and relative permeability remains unresolved. Additionally, we do not account for the diffusion of $\mathrm{scCO}_{2}$ into the water, which is important at long time scales and could lead to more of the network being expose to $\mathrm{scCO}_{2}$ and result in geochemical interactions between $\mathrm{scCO}_{2}$, water and fracture surface. Additional factors to take into consideration include the adopted functional form of relative permeability and transfer with the matrix surrounding the fracture network. The currently adopted boundary conditions (closed lateral boundaries) and open top boundary slightly influence the structure of the flow field near the lateral boundaries of the domain. If we considered open lateral boundaries, it would allow more $\mathrm{scCO}_{2}$ to flow through the 
domain and delay the arrival at quasi-steady state. These small numerical boundary effects would be eliminated, but the key results of the study, that network structure dominants over internal hydraulic properties, would remain the same. All of these scenarios deserve independent studies to better characterize their impact on our conceptual understanding of multiphase flow in fracture networks.

\section{Acknowledgments}

J.D.H., R.P, and P.S. are thankful for support from the US Department of Energy through the Los Alamos National Laboratory. Los Alamos National Laboratory is operated by Triad National Security, LLC, for the National Nuclear Security Administration of U.S. Department of Energy (Contract No. 89233218CNA000001). Specifically, J.D.H acknowledges support through the Laboratory-Directed Research and Development Program grants 20180621ECR. This work was completed as part of the National Risk Assessment Partnership (NRAP) project. Support for this project came from the U.S. Department of Energy's (DOE) Office of Fossil Energy's Coal Research program. The authors wish to acknowledge Traci Rodosta and Mary K. Underwood (NETL Strategic Center for Coal) and Mark Ackiewicz and Darin Damiani (DOE Office of Fossil Energy) for programmatic guidance, direction, and support. J.D.H. also thanks the partial support of DOE's Office of Science Basic Energy Sciences E3W1. J.J.M. acknowledges discretionary funding from EAWAG and Guest Scientist status from LANL. LA-UR-19-25316

\section{References}

1. Andrade, J.S., Costa, U.M.S., Almeida, M.P., Makse, H.A., Stanley, H.E.: Inertial effects on fluid flow through disordered porous media. Phys. Rev. Lett. 82, 5249-5252 (1999)

2. Bachu, S.: Sequestration of $\mathrm{CO} 2$ in geological media: criteria and approach for site selection in response to climate change. Energ. Convers. Manage. 41(9), 953-970 (2000)

3. Bachu, S., Adams, J.: Sequestration of $\mathrm{CO} 2$ in geological media in response to climate change: capacity of deep saline aquifers to sequester CO2 in solution. Energ. Convers. Manage. 44(20), 3151-3175 (2003)

4. Bell, R., Dean, P., Hibbins-Butler, D.: Localization of normal modes in vitreous silica, germania and beryllium fluoride. J. Phys. C Solid State 3(10), 2111 (1970)

5. Berre, I., Doster, F., Keilegavlen, E.: Flow in fractured porous media: A review of conceptual models and discretization approaches. Transport Porous Med. pp. 1-22 (2018)

6. Bickle, M.J.: Geological carbon storage. Nat. Geoscience 2(12), 815 (2009)

7. Birkholzer, J.T., Zhou, Q., Tsang, C.F.: Large-scale impact of $\mathrm{CO} 2$ storage in deep saline aquifers: A sensitivity study on pressure response in stratified systems. Int. J. Greenh. Gas. Con. 3(2), 181-194 (2009)

8. Bogdanov, I., Mourzenko, V., Thovert, J.F., Adler, P.: Effective permeability of fractured porous media with power-law distribution of fracture sizes. Phys. Rev. E 76(3), 036309 (2007)

9. Bonnet, E., Bour, O., Odling, N.E., Davy, P., Main, I., Cowie, P., Berkowitz, B.: Scaling of fracture systems in geological media. Rev. Geophys. 39(3), 347-383 (2001)

10. Chaudhuri, A., Rajaram, H., Viswanathan, H., Zyvoloski, G., Stauffer, P.: Buoyant convection resulting from dissolution and permeability growth in vertical limestone fractures. Geophys. Res. Lett. 36(3) (2009)

11. Class, H., Ebigbo, A., Helmig, R., Dahle, H.K., Nordbotten, J.M., Celia, M.A., Audigane, P., Darcis, M., Ennis-King, J., Fan, Y., et al.: A benchmark study on problems related to CO2 storage in geologic formations. Computat. Geosci. 13(4), 409 (2009)

12. Davy, P., Hansen, A., Bonnet, E., Zhang, S.Z.: Localization and fault growth in layered brittle-ductile systems: Implications for deformations of the continental lithosphere. J. Geophys. Res.-Sol. Ea. 100(B4), 6281-6294 (1995)

13. Davy, P., Le Goc, R., Darcel, C., Bour, O., De Dreuzy, J.R., Munier, R.: A likely universal model of fracture scaling and its consequence for crustal hydromechanics. J. Geophys. Res.-Sol. Ea. 115(B10) (2010) 
14. Deng, H., Molins, S., Trebotich, D., Steefel, C., DePaolo, D.: Pore-scale numerical investigation of the impacts of surface roughness: Upscaling of reaction rates in rough fractures. Geochim. Cosmochim. Ac. 239, 374-389 (2018)

15. Deng, H., Stauffer, P.H., Dai, Z., Jiao, Z., Surdam, R.C.: Simulation of industrial-scale CO2 storage: Multi-scale heterogeneity and its impacts on storage capacity, injectivity and leakage. Int. J. Greenh. Gas. Con. 10, 397-418 (2012)

16. Dershowitz, W.S., Herda, H.H.: Interpretation of fracture spacing and intensity. In: The 33th US Symposium on Rock Mechanics (USRMS). American Rock Mechanics Association (1992)

17. de Dreuzy, J.R., Davy, P., Bour, O.: Hydraulic properties of two-dimensional random fracture networks following power law distributions of length and aperture. Water Resour. Res. 38(12) (2002)

18. de Dreuzy, J.R., Méheust, Y., Pichot, G.: Influence of fracture scale heterogeneity on the flow properties of three-dimensional discrete fracture networks. J. Geophys. Res.-Sol. Ea. 117(B11) (2012)

19. Du, Q., Faber, V., Gunzburger, M.: Centroidal voronoi tessellations: Applications and algorithms. SIAM Rev. 41(4), 637-676 (1999)

20. Edwards, J., Thouless, D.: Numerical studies of localization in disordered systems. J. Phys C Solid State 5(8), 807 (1972)

21. Frampton, A., Hyman, J., Zou, L.: Advective transport in discrete fracture networks with connected and disconnected textures representing internal aperture variability. Water Resour. Res. 55(7), 5487-5501 (2019)

22. Hadgu, T., Karra, S., Kalinina, E., Makedonska, N., Hyman, J.D., Klise, K., Viswanathan, H.S., Wang, Y.: A comparative study of discrete fracture network and equivalent continuum models for simulating flow and transport in the far field of a hypothetical nuclear waste repository in crystalline host rock. J. Hydrol. 553, 59-70 (2017)

23. Hyman, J.D., , Karra, S., Carey, J.W., Gable, C.W., Viswanathan, H., Rougier, E., Lei, Z.: Discontinuities in effective permeability due to fracture percolation. Mech. Mater. 119, 25 - 33 (2018)

24. Hyman, J.D., Aldrich, G., Viswanathan, H., Makedonska, N., Karra, S.: Fracture size and transmissivity correlations: Implications for transport simulations in sparse three-dimensional discrete fracture networks following a truncated power law distribution of fracture size. Water Resour. Res. 52(8), 64726489 (2016). DOI 10.1002/2016WR018806

25. Hyman, J.D., Dentz, M., Hagberg, A., Kang, P.: Linking structural and transport properties in threedimensional fracture networks. J. Geophys. Res.-Sol. Ea. (2019)

26. Hyman, J.D., Gable, C.W., Painter, S.L., Makedonska, N.: Conforming Delaunay triangulation of stochastically generated three dimensional discrete fracture networks: A feature rejection algorithm for meshing strategy. SIAM J. Sci. Comput. 36(4), A1871-A1894 (2014)

27. Hyman, J.D., Hagberg, A., Osthus, D., Srinivasan, S., Viswanathan, H., Srinivasan, G.: Identifying backbones in three-dimensional discrete fracture networks: A bipartite graph-based approach. Multiscale Model. Sim. 16(4), 1948-1968 (2018)

28. Hyman, J.D., Jiménez-Martínez, J.: Dispersion and mixing in three-dimensional discrete fracture networks: Nonlinear interplay between structural and hydraulic heterogeneity. Water Resour. Res. 54(5), 3243-3258

29. Hyman, J.D., Karra, S., Makedonska, N., Gable, C.W., Painter, S.L., Viswanathan, H.S.: dfnWorks: A discrete fracture network framework for modeling subsurface flow and transport. Comput. Geosci. 84, $10-19(2015)$

30. Joyce, S., Hartley, L., Applegate, D., Hoek, J., Jackson, P.: Multi-scale groundwater flow modeling during temperate climate conditions for the safety assessment of the proposed high-level nuclear waste repository site at forsmark, sweden. Hydrogeol. J. 22(6), 1233-1249 (2014)

31. Karra, S., Makedonska, N., Viswanathan, H., Painter, S., Hyman, J.: Effect of advective flow in fractures and matrix diffusion on natural gas production. Water Resour. Res. 51(10), 8646-8657 (2015)

32. Keating, E.H., Newell, D.L., Viswanathan, H., Carey, J., Zyvoloski, G., Pawar, R.: CO2/brine transport into shallow aquifers along fault zones. Environ. Sci. Technol. 47(1), 290-297 (2012)

33. LaGriT: Los Alamos Grid Toolbox, (LaGriT) Los Alamos National Laboratory. http://lagrit.lanl.gov (2013)

34. Lovell, A.E., Srinivasan, S., Karra, S., O’Malley, D., Makedonska, N., . Viswanathan, H.S., Srinivasan, G., Carey, J.W., Frash, L.P.: Extracting hydrocarbon from shale: An investigation of the factors that influence the decline and the tail of the production curve. Water Resour. Res. (2018)

35. Maillot, J., Davy, P., Le Goc, R., Darcel, C., De Dreuzy, J.R.: Connectivity, permeability, and channeling in randomly distributed and kinematically defined discrete fracture network models. Water Resour. Res. 52(11), 8526-8545 (2016)

36. Makedonska, N., Hyman, J.D., Karra, S., Painter, S.L., Gable, C.W.W., Viswanathan, H.S.: Evaluating the effect of internal aperture variability on transport in kilometer scale discrete fracture networks. Adv. Water Resour. 94, 486-497 (2016) 
37. Mourzenko, V., Thovert, J.F., Adler, P.: Percolation of three-dimensional fracture networks with powerlaw size distribution. Phys. Rev. E 72(3), 036103 (2005)

38. Mudunuru, M.K., Karra, S., Makedonska, N., Chen, T.: Sequential geophysical and flow inversion to characterize fracture networks in subsurface systems. Stat. Anal. Data. Min. 10(5), 326-342 (2017)

39. Oh, J., Kim, K.Y., Han, W.S., Park, E., Kim, J.C.: Migration behavior of supercritical and liquid CO2 in a stratified system: Experiments and numerical simulations. Water Resour. Res 51(10), 7937-7958 (2015)

40. Porter, M.L., Plampin, M., Pawar, R., Illangasekare, T.: CO2 leakage in shallow aquifers: A benchmark modeling study of $\mathrm{CO} 2$ gas evolution in heterogeneous porous media. Int. J. Greenh. Gas. Con. 39, 51-61 (2015)

41. Raduha, S., Butler, D., Mozley, P., Person, M., Evans, J., Heath, J., Dewers, T., Stauffer, P., Gable, C., Kelkar, S.: Potential seal bypass and caprock storage produced by deformation-band-to-opening-modefracture transition at the reservoir/caprock interface. Geofluids 16(4), 752-768 (2016)

42. Rutqvist, J., Tsang, C.F.: A study of caprock hydromechanical changes associated with CO2-injection into a brine formation. Environ. Geol. 42(2-3), 296-305 (2002)

43. Saadatpoor, E., Bryant, S.L., Sepehrnoori, K.: New trapping mechanism in carbon sequestration. Transport Porous Med. 82(1), 3-17 (2010)

44. Sanchez-Vila, X., Guadagnini, A., Carrera, J.: Representative hydraulic conductivities in saturated groundwater flow. Rev. Geophys. 44(3) (2006)

45. Seidman, S.B.: Network structure and minimum degree. Soc. Networks 5(3), 269 - 287 (1983)

46. Shukla, R., Ranjith, P., Haque, A., Choi, X.: A review of studies on CO2 sequestration and caprock integrity. Fuel 89(10), 2651-2664 (2010)

47. Svensk Kärnbränslehantering AB: Data report for the safety assessment SR-site (TR-10-52). Tech. rep., Svensk Kärnbränslehantering AB (2010)

48. Ushijima-Mwesigwa, H., Hyman, J.D., Hagberg, A., Safro, I., Karra, S., Gable, C.W., Srinivasan, G.: Multilevel graph partitioning for three-dimensional discrete fracture network flow simulations. arXiv preprint arXiv:1902.08029 (2019)

49. Watson, F.E., Mathias, S.A., van Hunen, J., Daniels, S.E., Jones, R.R.: Dissolution of co 2 from leaking fractures in saline formations. Transport Porous Med. 94(3), 729-745 (2012)

50. Wellman, T.P., Shapiro, A.M., Hill, M.C.: Effects of simplifying fracture network representation on inert chemical migration in fracture-controlled aquifers. Water Resour. Res. 45(1) (2009)

51. Witherspoon, P.A., Wang, J., Iwai, K., Gale, J.: Validity of cubic law for fluid flow in a deformable rock fracture. Water Resour. Res. 16(6), 1016-1024 (1980)

52. Wood, A.T.: Simulation of the von Mises Fisher distribution. Commun. Stat. Simulat. 23(1), 157-164 (1994)

53. Zyvoloski, G.: FEHM: A control volume finite element code for simulating subsurface multi-phase multi-fluid heat and mass transfer. Los Alamos Unclassified Report LA-UR-07-3359 (2007) 